\title{
Comparison of the upper, middle, and lower vertical facial height between Down syndrome and normal children
}

\author{
Nor Dayana Mohammad Ali*, Rudy Hartanto*, Meirina Gartika** \\ *Department of Oral Biology Faculty Of Dentistry Universitas Padjadjaran \\ **Department of Pedodontics Faculty Of Dentistry Universitas Padjadjaran
}

\section{ABSTRACT}

Introduction: Down syndrome (DS) is a common genetic disorder also known as Trisomy 21.DS individuals have specific physical dysmorphism especially the face. The most common features and problems associated with Down's syndrome are characteristic facial features, cognitive problems, congenital heart disease, hearing problems, short stature, thyroid problems and Alzheimer's disease. This study aims to determine the differences of the vertical facial height measurement (UFH, MFH and LFH) between DS and regular (R) children. Methods: The study is a Cross-sectional analytical. Subjects are 6-13 years of age, with a total of 20 DS children (10 males; 10 females) of selected Sekolah Luar Biasa-C (SLB- Cs) and 160 R school children (80 males; 80 females) from selected Sekolah Dasar Negeri (SDNs) in Kota Bandung. Subjects selected using the three levels Multi stage cluster sampling. Measurements taken were upper, middle and lower facial height with each measurement taken three times. Data was analysed using the t-test and p-value. Results: UFH in DS males are 5.623, 5.986, 6.352, 6.396, 6.585, 6.747,7.109; MFH 3.325, 3.456, 3.457, 3.646, 3.611, 3.720, 3.716 and LFH are 4.163, 4.283, 4.235, 4.771, 4.850, 4.979, 5.132. UFH in R males are 5.924, 6.029, 6.223, 6.362, 6.476, 6.725, 6.903, 7.366; MFH 3.942, 3.998, 4.103, $4.148,4.175,4.247,4.463,4.534$ and LFH 4.509, 4.658, 4.882, 5.058, 5.167, 5.450, 5.532, 5.606. In DS females UFH are 5.745, 5.912, 5.986, 6.394, 6.339, 6.778; MFH 3.575, 3.704, 3.711, 3.768, 3.749, 3.865 and LFH 4.49, 4.552, 4.646, 4.909, 5.034, 5.039. UFH for R females 6.062, 6.167, 6.243, 6.308, 6.476, 6.515, 6.799, 6.965; MFH 3.700, 3.863, 3.981, 4.084,4.091, 4.116, 4.191, 4.221 and LFH 4.576, 4.702, 3.764, 4.998, 5.156, 5.326, 5.374, 5.552 (in cm). Conclusion: There are significant differences with the MFH and LFH between DS and R children and UFH differences is non significant between these two populations.

Keywords: Down syndrome, regular children, UFH, MFH and LFH.

\section{INTRODUCTION}

Down Syndrome (DS) is one of the most frequently occurring chromosomal abnormalities occurring nowadays. It is also known as Trisomy 21 or Mongolism, however the term Mongolism is rarely used at present. DS occurs between 1 in 600 births and 1 in 1000 births. ${ }^{1,2}$ DS can be found in all ethnic communities as it affects people of all ages, races and economic levels.

Down syndrome leads to mental retardation and malformation in a newborn. In 1959, with the advancement of karyo-typing technology, the etiology of DS was identified as the presence of an extra chromosome $21 .{ }^{3}$ The presence of an extra chromosome causes excess in chromosome 
21, making it a total of three chromosomes of chromosome $21 .{ }^{4}$ Hence, it is called "Trisomy 21".

An English physician, John Langdon Down, had discovered and published an accurate description of an individual with DS during the late nineteenth century. ${ }^{3}$ This remarkable discovery had landed him the title, "Father" of the syndrome. He also described the condition as a distinct and separate entity.

There are three known types of Down syndrome; (1) Full Trisomy (Non-disjunction), (2) Mosaicism and (3) Translocation. Full Trisomy is the most commonly occurring type in it, which occurs $95 \%$ of the time. ${ }^{5}$ As for Mosaicm and Translocation, each occurs approximately 1-2\% and $2-3 \%$ respectively.

The occurrence of DS is closely related to gene abnormalities. Cyril et al, suggested that genenutrient interactions associated with abnormal folate metabolism and DNA hypomethylation leads to the increase of chromosomal non-disjunction.

One of the key risk factors associated with increasebirth incidences of children with DS increases with the age of the mother. ${ }^{5}$

Children undergo multiple changing processes starting from birth, which includes physical, psychological and physiological changes during growth and development. Nonetheless, growth and development of each child varies as some may have higher growth rates compared to others. Regardless of their racial background, DS children tend to have specific characteristics that distinguish them from the normal children.

The most common features and problems associated with Down's syndrome are characteristic facial features, cognitive problems, congenital heart disease, hearing problems, short stature, thyroid problems and Alzheimer's disease. In general, they are characterised by retarded physical development such as shorter than normal height, stubby fingers, distinctive facial structures such as flat profile, flat bridge of the nose, smaller than normal low-set nose, small mouth and large tongue, slanting eyes, and round head as well as mental retardation. Medically they are often associated with diseases such as kidney defects, suppressed immune system and malformations of the heart, ears, hands and feet. ${ }^{4}$ Down syndrome individuals also tend to have shorter life expectancy and sexual maturity is seldom attained.

In a review on Down syndrome by the Southern Association of Institutional Dentists, they described that mid-face dysplasia is a cardinal characteristic of Down syndrome individual. They also mentioned other facial characteristics include nose malformations (a flat broad bridge), ear malformations including "lop" ears, low set ears, ears with flat or absent helix, eye malformations (epicanthal folds with slanting almond-shaped eyes which is also known as Mongoloid). Apart from that, Down syndrome individuals also exhibit brachycephaly (broad, short head), lack of supraorbital ridges and hypotelerism, absence of frontal sinuses and absent or reduced maxillary sinuses and nasal septum or nasal conchal deviations. ${ }^{6}$

Facial proportions and height differs depending on theage, gender, racial background and whether individual is suffering from any syndromes or facial malformations. The differences in facial growth, development and proportions can be seen clearly especially in Down syndrome individuals. Facial anthropometric studies involving facial height have vast implications in health related fields and are useful for orthodontists, plastic surgeons, maxillofacial surgeons as well as for anthropologists and forensic facial reconstruction experts. ${ }^{7}$ Anthropometry is the measurement of the body and its part. ${ }^{8}$ Anthropometric study serves as a useful tool in examining the human facial proportions, and in this case the facial proportions of the Down syndrome and normal children.

The deviant physical development in Down syndrome can be effectively illustrated anthropometrically. ${ }^{9}$ The vertical facial height can be divided into three parts as described by Kulkarni N. and M. Kohli, the upper third of face is from hairline to supra-orbital ridge (UFH), the middle third of the face represents from supraorbital ridge to base of nose (MFH) and the lower third of face represents from base of nose to chin (LFH). In a study done by Suri $\mathrm{S}$ et al. concluded that large reductions were measured in the size and spatial relationships of craniofacial structures in the Down syndrome group.

In the study, other results attained was that the greatest differences included a larger cranial base angle; reduced anterior and posterior cranial base lengths; reduced anterior 
and posterior face heights; smaller maxilla with reduced anterior basal and apical dimensions; and smaller mandibular ramus, body and symphyseal dimensions and pro-clined symphysis.

The health care aspects of Down's syndrome include anticipating and preventing the known adverse effects of the condition it self. Also, recognizing complications that could arise from the genetic disorder, managing symptoms as they come up, and helping the person with Down's syndrome and family members with understanding and coping with the disorder.

Not many studies have been carried out on examining and comparing the growth and development of the Down syndrome children in comparison to normal children. Thus, the author is interested in doing research about the facial proportions of the Down syndrome children and normal children using the anthropometric method. Craniofacial anthropometry provides a simple and non-invasive method of quantitative assessment of changes in the surface anatomy of the head and face in individuals with Down syndrome. ${ }^{10}$

\section{METHODS}

This particular research is a Cross-sectional analytical type of study. The study employs surveying technique in order to distinguish clearly the differences of the vertical facial height measurements of Down syndrome children from the regular primary school children in Kota Bandung.

The study was conducted throughout the month of May 2011. In order to obtain the samples for the Down syndrome (DS) children as well as the regular $(R)$ primary school children, the three levels of Multi stage cluster random sampling were used. Kota Bandung is comprised of five main regions, which include: Bandung Utara, Bandung Timur, Bandung Selatan, Bandung Barat and Bandung Tengah. In choosing the Sekolah Luar Biasa- C (SLB-C) for the DS samples and Sekolah Dasar Negeri (SDN) for the R children samples, three levels of Multi stage cluster random sampling technique is used. From the sampling technique, out of the five regions, only one region was selected in order to avoid any bias in sample selection. Thus, from the random sampling, region I (Bandung Utara) was chosen as the region of study.

Therefore, the schools for both sample populations are selected from the Bandung Utara region.

At the third level, however, population sampling was used in choosing the DS subjects due to the limited number of primary school DS children available. On the other hand, simple random sampling was used in choosing the samples for the R children.

The criteria required for a suitable DS sample candidate are: primary school children of ages 6-13 years old, suffering from Down syndrome, is not suffering from other genetic or congenital disorders, those attending the selected SLB-Cs and those who were given consent by their parents or guardian to be involved in the study.

\section{RESULTS}

The bar graph 1 shows the the frequency of the Down Ssyndrome (DS) and normal (R) sample distribution. There are 20 DS subjects (10 males and 10 females) whereas there are 160 (80 males and 80 females) normal (control) subjects ages from 6 to 13 years old. There are even number of normal samples in which there is 10 males and 10 females in each group. However, for DS children, the distribution is rather uneven due to the limited number of samples available.

Table 1 shows the mean as well as the standard deviation for the male DS and R school children for each age group. The means were calculated and presented in centimetres $(\mathrm{cm})$. The symbol asterisk $\left({ }^{*}\right)$ indicates that there

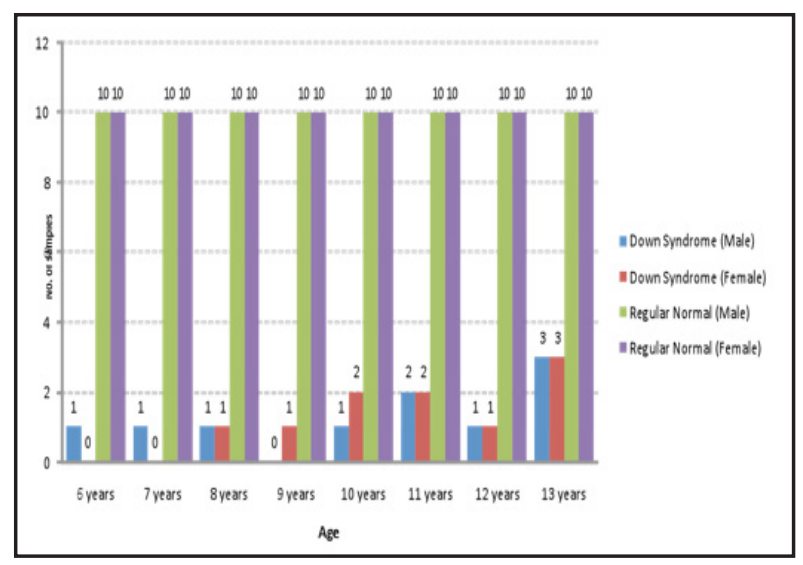

Grafik 1. Distribution of the research sample frequency according to age and gender 
Table 1. Table showing the mean (in $\mathrm{cm}$ ) of the down syndrome and normal male children group according to age

\begin{tabular}{ccccccc}
\hline Age & \multicolumn{3}{c}{ Normal Children (R) } & \multicolumn{3}{c}{ Down Syndrome Children (DS) } \\
\hline Year & $\begin{array}{c}\text { Mean } \\
\text { UFH }(\mathrm{cm})\end{array}$ & $\begin{array}{c}\text { Mean } \\
\text { MFH }(\mathrm{cm})\end{array}$ & $\begin{array}{c}\text { Mean } \\
\text { LFH }(\mathrm{cm})\end{array}$ & $\begin{array}{c}\text { Mean } \\
\text { UFH }(\mathrm{cm})\end{array}$ & $\begin{array}{c}\text { Mean } \\
\text { MFH }(\mathrm{cm})\end{array}$ & $\begin{array}{c}\text { Mean } \\
\text { LFH }(\mathrm{cm})\end{array}$ \\
\hline 6 & $5.924 \pm 0.180$ & $3.942 \pm 0.079$ & $4.509 \pm 0.248$ & 5.623 & $3.325^{*}$ & 4.163 \\
7 & $6.029 \pm 0.235$ & $3.998 \pm 0.211$ & $4.658 \pm 0.217$ & 5.986 & 3.456 & 4.283 \\
8 & $6.223 \pm 0.190$ & $4.103 \pm 0.164$ & $4.882 \pm 0.260$ & 6.352 & $3.457^{*}$ & $4.235^{*}$ \\
9 & 6.362 & 4.148 & 5.058 & N/A & N/A & N/A \\
10 & $6.476 \pm 0.245$ & $4.175 \pm 0.225$ & $5.167 \pm 0.274$ & 6.396 & 3.646 & 4.771 \\
11 & $6.725 \pm 0.333$ & $4.247 \pm 0.098$ & $5.450 \pm 0.227$ & $6.585 \pm 0.087$ & $3.611 \pm 0.117^{*}$ & $4.850 \pm 0.287^{*}$ \\
12 & $6.903 \pm 0.370$ & $4.463 \pm 0.141$ & $5.532 \pm 0.169$ & 6.747 & $3.720^{*}$ & $4.979^{*}$ \\
13 & $7.366 \pm 0.268$ & $4.534 \pm 0.117$ & $5.606 \pm 0.113$ & $7.109 \pm 0.037$ & $3.716 \pm 0.014^{*}$ & $5.132 \pm 0.025^{*}$ \\
\hline
\end{tabular}

*Statistically significant difference between DS and R measurements; UFH = Upper facial height; MFH= Middle facial height; LFH= Lower facial height; N/A = Not available

is significant difference in terms of statistics between the DS and R primary school children. For the 6 year old DS male, the mean for the UFH, MFH and LFH are 5.623, 3.325 and 4.163. For the $\mathrm{R}$ children, they have larger means which are $5.924,3.942$ and 4.509 respectively. The tables showing the $\mathrm{p}$-values and standard deviations can be reffered at the Appendix section. Statistically, the UFH and LFH between DS and R children differs non significantly as the $\mathrm{p}$-value is larger than alpha (a) (UFH: $0,146>0,05$; LFH: 0.217 $>0,05)$ which indicates that $\mathrm{HO}$ is accepted as there is no significant difference of measurement between the two populations. However, the MFH differs significantly as the $\mathrm{p}$-value is smaller than a $(0,000<0,05)$. Hence, $\mathrm{H} 1$ is accepted as there is significant differences in the measurement between DS and R subjects.

The mean measurements for the UFH, MFH and LFH of the 7 year old male DS are 5.986, 3.456 and 4.283. Meanwhile, the mean for the R children are $6.029,3.998$ and 4.658 , which are somewhat larger than the DS group. From the statistic table (Appendix 8, Table 5), it is indicated that the differences in UFH is insignificant as the $p$-value is bigger than $\alpha(0,866>0,05)$ and the same applies for the LFH $(0,134>0,05)$. This means that $\mathrm{HO}$ is accepted. However, the MFH between populations have significant differences as $\mathrm{p}$-value is smaller than alpha $(0,025<0,05)$ which indicates that $\mathrm{H} 1$ is accepted.

From the table 1. above, the mean for the 8 year old DS males for UFH, MFH and LFH measurements are $6.352,3.457$ and 4.235 respectively. The $\mathrm{R}$ male children have means of 6.223, 4.103 and 4.882. The $p$-value of the UFH in DS is bigger than a $(0,533>0,05)$ which indicates that the difference is statistically insignificant thus, accepting the HO. The MFH and LFH differs significantly between the $D S$ and $R$ as the $p$-values are smaller than a $(\mathrm{MFH}: 0,004<0,05$ and LFH: $0,042<0,05)$. Therefore the $\mathrm{H} 1$ are accepted as the differences are statistically significant.

For the 9 years old male, the average for UFH, MFH and LFH for the DS children is not available as there is no sample of that age. However, for the R children, they have UFH, MFH and LFH means of $6.362,4.148$ and 5.058. Statistically the measurements cannot be compared due to the inavailability of the DS measurements.

The mean for the 10 years old DS male for the UFH is 6.396, MFH is 3.646 and LFH is 4.771. On the other hand, the means for the R children are slightly large which are 6.476 for UFH, 4.175 for MFH and 5.167 for LFH. The p-value for the UFH is larger than a which indicates that the difference is insignificant $(0,762>0,05)$ therefore, thus, $\mathrm{HO}$ is accepted. The MFH $(0,052>0,05)$ as well as the LFH have a bigger $p$-value than a $(0,202>0,05)$ which means that the difference is insignificant. Thus, HO is accepted, as there are insignificant differences in the measurements.

From table 1., for the 11 year olds DS, the means of the UFH, MFH and LFH are 6.585, 3.611 and 4.850. Meanwhile, for the R children, the mean measurements are 6.725, 4.247 and 5.450. Statistically, the UFH does not differ sgnificantly $(0,581>0,05)$ between these two groups thus; HO 
is accepted, as there is an insignificant difference in the measurements. The MFH and LFH differs significantly as the $\mathrm{p}$-values are smaller than $a$ (MFH: 0,000 < 0,05 and LFH: 0,008<0,05) hence, $\mathrm{H} 1$ is accepted as there are significant differences in the measurements.

In the 12 year olds DS, the mean of the UFH is 6.747, MFH is 3.720 and LFH is 4.979 . Whereas, the means for the R children are 6.903, 4,463 and 5.532 respectively. The UFH is statistically not significant as the $\mathrm{p}$-value is bigger than a $(0,747$ $>0,05$ ) thus accepting $\mathrm{HO}$. However, the MFH and LFH have significant differences (MFH: 0,001 < $0,05$ and LFH: $0,012<0,05)$ indicating that the $\mathrm{H} 1$ is accepted, as there are significant differences in the measurements.

Table 1 also shows the mean results for the 13 years old DS males as well as the $\mathrm{R}$ children. The mean of the UFH, MFH and LFH for the DS children are 7.109, 3.716 and 5.132. Meanwhile, for the R children are 7.366, 4.534 and 5.606. From the statistical analysis, it is found that the UFH does not differ significantly $(0,137>0,05)$ thus, $\mathrm{HO}$ is accepted, as there are insignificant differences in the measurements. On the other hand, the MFH and LFH differs significantly with values of $(0,000<0,05$ and $0,000<0,05)$ between the two population samples. Thus, $\mathrm{H} 1$ are accepted, as there are significant differences in the measurements.

Graphs 2, 3 and 4. shows the UFH, MFH and LFH of the male DS and the regular children according to age group. The value used to plot the graph are the mean values (in $\mathrm{cm}$ ) as the $y$-axis and the age group as the $\mathrm{x}$-axis. For the 9 year olds DS, all three bar graph plots at 0 as there is no sample of that age available.

Table 2. above shows the results of the mean measurements of the UFH, MFH and LFH for the DS females as well as the R primary school children from the age of 6 to 13 years old. As there is no 6-year-old DS female sample, thus there is no data available. However, the regular children of 6 year old have a mean of UFH, MFH and LFH of 6.062, 3.700 and 4.576. The data cannot be analysed statistically due to the unavailable DS data. For the 7-year-old females, the DS data is also unavailable as there is no sample of that age. The regular children however, have means of 6.167, 3.863 and 4.702 for the UFH, MFH and LFH. Like

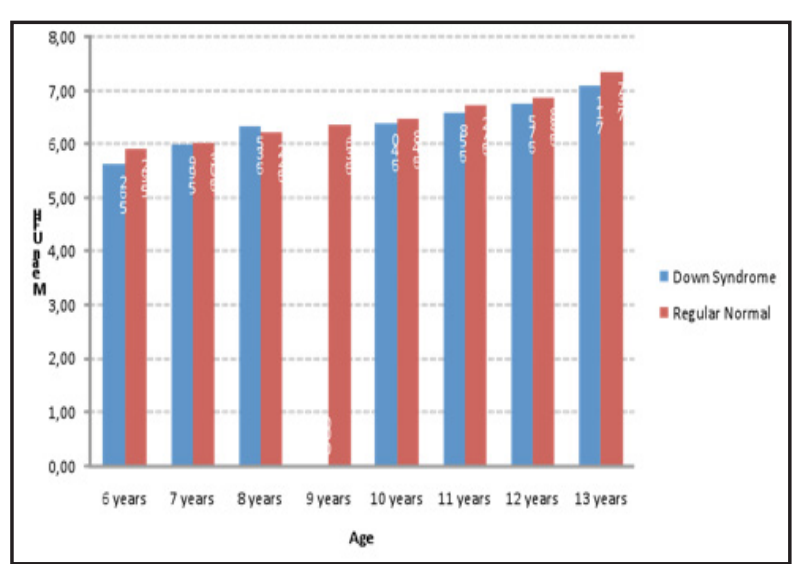

Table 2. Table showing the mean (in $\mathrm{cm}$ ) of the down syndromeand normal female children group according to age

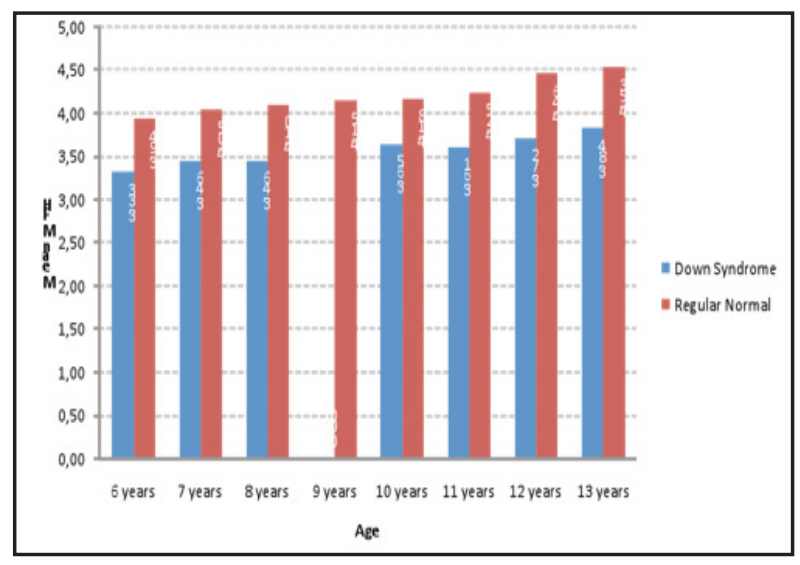

Graph 2. The upper facial height (mean, $\mathrm{cm} ; \mathrm{y}$-axis) of down syndrome and normal male children according to age group (x-axis)

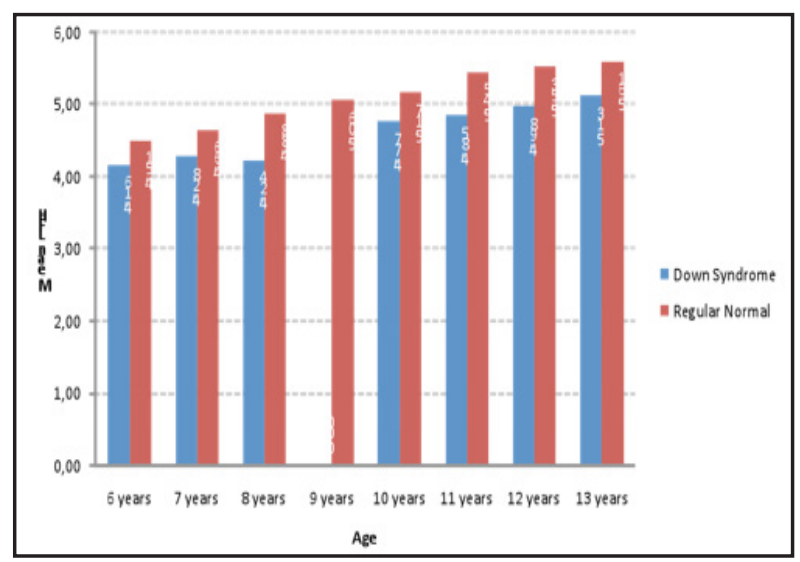

Graph 3. The middle facial height (mean, $\mathrm{cm}$; y-axis) of down syndrome and normal male children according to age group (x-axis)

the 6 year olds, the 7-year-old group also cannot be statistically analysed there is no available data for the DS group. 
Graph 4. The lower facial height (mean, $\mathrm{cm} ; \mathrm{y}$-axis) of down syndrome and Normal male children according to age group (x-axis)

\begin{tabular}{clccccc}
\hline Age & \multicolumn{3}{c}{ Normal Children (R) } & \multicolumn{2}{c}{ Down Syndrome Children (DS) } \\
\hline Year & $\begin{array}{c}\text { Mean } \\
\text { UFH }(\mathrm{cm})\end{array}$ & $\begin{array}{c}\text { Mean } \\
\text { MFH }(\mathrm{cm})\end{array}$ & $\begin{array}{c}\text { Mean } \\
\text { LFH }(\mathrm{cm})\end{array}$ & $\begin{array}{c}\text { Mean } \\
\text { UFH }(\mathrm{cm})\end{array}$ & $\begin{array}{c}\text { Mean } \\
\text { MFH }(\mathrm{cm})\end{array}$ & $\begin{array}{c}\text { Mean } \\
\text { LFH }(\mathrm{cm})\end{array}$ \\
\hline 6 & 6.062 & 3.700 & 4.576 & N/A & N/A * & N/A \\
7 & 6.167 & 3.863 & 4.702 & N/A & N/A & N/A \\
8 & $6.243 \pm 0.261$ & $3.981 \pm 0.070$ & $3.764 \pm 0.177$ & 5.745 & $3.575^{*}$ & $4.449 *$ \\
9 & $6.308 \pm 0.263$ & $4.084 \pm 0.106$ & $4.998 \pm 0.206$ & 5.912 & $3.704^{*}$ & 4.552 \\
10 & $6.476 \pm 0.286$ & $4.091 \pm 0.087$ & $5.156 \pm 0.293$ & $5.986 \pm 0.056^{*}$ & $3.711 \pm 0.053^{*}$ & $4.646 \pm 0.061^{*}$ \\
11 & $6.515 \pm 0.295$ & $4.116 \pm 0.108$ & $5.326 \pm 0.232$ & $6.394 \pm 0.056$ & $3.768 \pm 0.001^{*}$ & $4.909 \pm 0.158^{*}$ \\
12 & $6.799 \pm 0.336$ & $4.191 \pm 0.106$ & $5.374 \pm 0.211$ & 6.339 & $3.749^{*}$ & 5.034 \\
13 & $6.965 \pm 0.333$ & $4.221 \pm 0.096$ & $5.552 \pm 0.233$ & $6.778 \pm 0.247$ & $3.865 \pm 0.040^{*}$ & $5.039 \pm 0.089^{*}$ \\
\hline
\end{tabular}

*Statistically significant difference between DS and R measurements; UFH = Upper facial height; MFH= Middle facial height; LFH= Lower facial height; N/A = Not available

From table 2., the means of the UFH, MFH and LFH for the DS females and regular females of ages 8 years old are shown. DS children have means of $5.745,3.575$ and 4.449 which is generally different compared to the $\mathrm{R}$ children with means of $6.243,3.981$ and 3.764 respectively. When statistically analysed, the UFH of these two groups does not differ significantly $(0,102>0,05)$ which indicated that $\mathrm{HO}$ is accepted that means there is no difference in the measurements. The MFH differs significantly as the $\mathrm{p}$-value is smaller than alpha $(0,000<0,05)$ thus, $\mathrm{H} 1$ is accepted as there are significant differences in the measurements. The LFH is not significant as the p-value is bigger than alpha $(0,123>0,05)$ hence, $\mathrm{HO}$ is accepted indicating that there are no significant differences between the measurements. The statistical tables can be referred to at the Appendix 8. For the 9 year olds, the DS have a UFH mean of 5.912, MFH of 3.704 and LFH of 4.552 . On the other hand, the $R$ children have a larger means of $6.308,4.084$ and 4.998 respectively.

Statistically the UFH and LFH do not differ significantly $(0,185>0,05$ and $0,069>0,05)$ thus, $\mathrm{HO}$ is accepted which indicates that there are no significant differences with the measurements between the two populations. However the MFH differs significantly as the $\mathrm{p}$-value is smaller than alpha $(0,008<0,05)$ that means that the $\mathrm{H} 1$ is accepted, as there are significant differences in the measurement. In the 10 year olds, the means of the UFH, MFH and LFH in the DS are 5.986, 3.711 and 4.646 meanwhile the means for the regular children are 6.476, 4.091 and 5.156. Statistically the UFH, MFH and LFH all differs significantly at the p-values are smaller than alpha $(0,042<$ 0,$05 ; 0,000<0,05$ and $0,039<0,05$ ) hence, $\mathrm{H} 1$ are accepted for all three as there are significant differences in the measurements.

Table 2. also shows the mean results of the 11 years olds females DS and regular. For the DS females, the UFH is 6.394, MFH is 3.768 and LFH is 4.909. For the $\mathrm{R}$ children, the means are slightly larger, 6.515, 4.116 and 5.326. When statistically analysed, the UFH is insignificant between these two populations $(0,586>0,05)$ which means that $\mathrm{HO}$ is accepted as the difference are non significant. However, for the MFH and LFH both measurements differ significantly $(0,000<0,05$ and $0,027<0,05)$ thus, $\mathrm{H} 1$ is accepted, as there are significant differences in the measurements. For the 12-year-old females, the DS have UFH, MFH and LFH means of 6.339, 3.749 and 5.034. Meanwhile, the $\mathrm{R}$ children have larger means of 6.799, 4.191 and 5.374.

Statistically, the UFH and LFH does not differ significantly as the $\mathrm{p}$-values are bigger than alpha $(0,226>0,05$ and $0,158>0,05)$ thus, $\mathrm{H} 0$ is accepted as there are insignificant differences in the measurements. The MFH is significantly different between the two groups $(0,003<0,05)$ therefore clearly accepting $\mathrm{H} 1$ as there are significant differences in the measurements. From table 2. also, the means for the 13 years olds are shown. The DS have means of 6.778 for the UFH, 3.865 for the MFH and 5.039 for the LFH. For the regular children, the means are 6.965 for UFH, 4.221 for the MFH and 5.552 for the LFH. When 


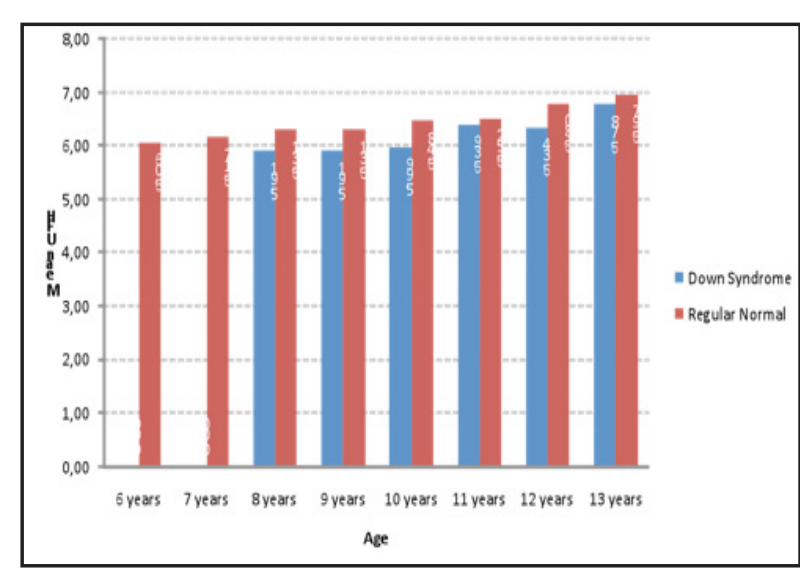

Graph 5. The upper facial height (mean, $\mathrm{cm}$; y-axis) of down syndrome and normal female children according to age group (x-axis)

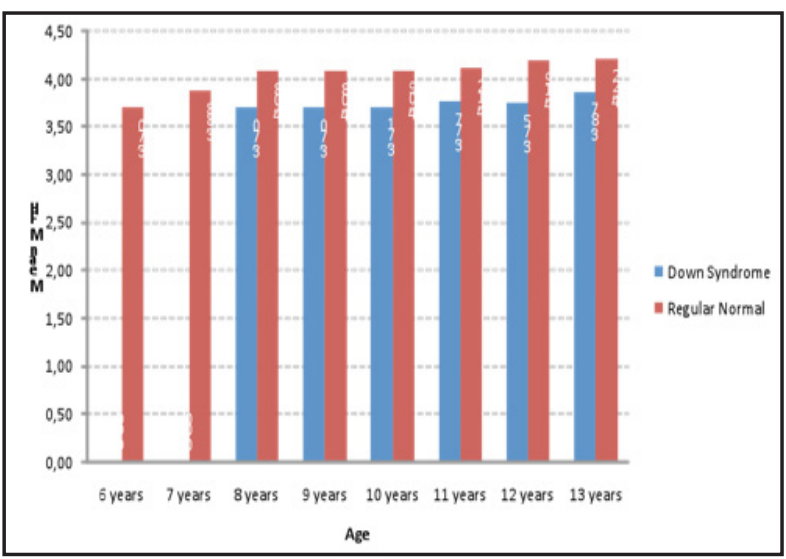

Graph 6. The middle facial height (mean, $\mathrm{cm}$; y-axis) of down syndrome and normal female children according to age group ( $x$-axis)

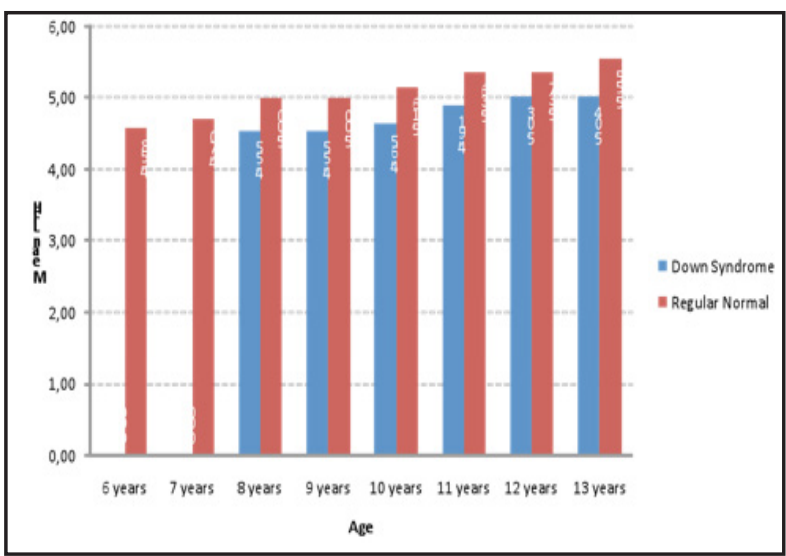

Graph 4.7 The lower facial height (mean, $\mathrm{cm}$; y-axis) of down syndrome and normal female children according to age group ( $\mathrm{x}$-axis)

statistically analysed, the UFH is insignificant $(0,391>0,05)$ thus accepting the $\mathrm{H} 0$ due to the insignificant differences. The MFH and LFH are significant between both groups as the $p$-values are smaller than alpha $(0,000<0,05$ and 0,004< $0,05)$ thus, $\mathrm{H} 1$ is accepted as there are significant differences in the measurements. Graph 5, 6 and 7 shows the plotted mean values of the UFH, MFH and LFH for each age group for the female DS and $\mathrm{R}$ children.

\section{DISCUSSION}

Anthropometry is a useful, effective and accurate tool in illustrating the deviant physical development in Down syndrome. It is a non-invasive method and measurements are taken on the soft tissue landmarks. With the results obtained from the study, the mean of each measurement (UFH, $\mathrm{MFH}$ and LFH) were calculated and then averaged according to the specific age group and gender.

Statistical analysis was used in order to find the standard deviation, for the t-testand to find the $p$-value (Z-score) in order to see if there are any statistically significant differences in the measurements. P-value that is less than alpha value $(p<0,05)$ indicates that the differences is significant and if $p>0,05$ shows that the differences is not significant. The standard deviations, $\mathrm{p}$-values and alpha values can be referred to in Appendix 8 section.

As described by Farkas, L.G., 1994, the statistical analysis of population data provides a quantitative foundation in estimating the normality or beauty of the human head and face. In addition, their features are of obvious value to plastic surgeons, but also for clinicians and researchers in other areas as well. Moreover, Jaswal S, Jaswal IJS ${ }^{9,10}$, also mentioned that in their study, all physical measurements were changed to standard scores or Z-scores so that subjects of different ages and sex can be compared. ${ }^{9,10}$

The results are compared between the DS children subjects (investigated group) and the $\mathrm{R}$ school children subjects (control group) of the same age group and same gender. Overall, there are six hypotheses in total to be tested ( 3 for males and 3 for females). The results from the study revealed that there are significant differences in the vertical facial height especially in the middle and lower facial height. However, there are slight but rather insignificant differences statistically with the upper facial height measurements between these two populations. 
From the result, for the males, the UFH differences are statistically insignificant between these two populations as $p>0,05$. However, this is rather inconclusive for DS of 9 years of age as there was no sample available to be compared with the R sample of the same age. Hence, the hypothesis cannot be tested between the DS and $\mathrm{R}$ male children.

The MFH difference between the DS and $\mathrm{R}$ males are overall significant for all age group with exception for 9 and 10 years of age. Hence, hypothesis $\mathrm{H} 1$ is accepted if $\mathrm{p}<0,05$, where there is a marked difference or significant difference in the UFH measurement between the DS compared to the $\mathrm{R}$ male children.

The differences of the lower $1 / 3$ of the facial height, the LFH, are mostly significant. It is significant maybe mainly due to the pubertal spurt period in males, which occur around the age 12 and 14 years old as stated by Rakosi T., et al, 1993.11 Hypothesis $\mathrm{H} 1$ is accepted if $\mathrm{p}<0,05$, where there is a marked difference or significant difference in the UFH measurement between the $\mathrm{DS}$ and $\mathrm{R}$ male children for these age group.

On the other hand, for the females, the differences in the UFH, MFH and LFH cannot be calculated statistically for samples of age 6 and 7 years old, as there was no sample available at that particular age. The UFH measurements over all are insignificant between both DS and R female populations with an exception for the age group of 10 years old in which the result showed that there is a significant difference $(0,042<0,05)$. Thus, $\mathrm{H} 0$ is accepted if $\mathrm{p}>0,05$, where there is no difference or insignificant difference in the UFH measurement between the DS and the R female children.

As for the MFH, hypothesis $\mathrm{H} 1$ is accepted as $p<0,05$, where there is a significant difference in the UFH measurement between the DS and R female children of all age group. Furthermore, the LFH are generally significant. This may be due to the growth spurt in females occurs much early than males. Hence, $\mathrm{Hi}$ is accepted an indication that there is a significant difference in the measurement between the DS and R female children.

In this particular study, overall, by referring to the mean values, the measurements of the UFH, MFH and LFH were considerably reduced in the DS subjects compared to the R subjects. This is consistent with the findings by Jaswal, S. and IJS Jaswal in 1981 which stated that Down syndrome were observed to be below normal for almost every measurement and there were obvious reduction in the linear measurements.

Ferrario VF et $\mathrm{al}^{12}$, discovered that independently of sex, subjects with Down syndrome had faces that were significantly ( $P$ $<0.05$, paired Student ttest) narrower mandible, less deep (upper, middle, and lower face), and shorter (face and nose height) than the faces of normal subjects. In addition, they also stated that facial height was significantly different between sexes. This is consistent with the outcome of this study. ${ }^{12}$

In another study done by Farkas, L.G., et al, 2001, found that the highest percentage of mild-moderate disproportion was found in the face of DS subjects (79.3\%). This outcome leads to a smaller total facial height which is similar with what was found by Ferrario VV et al, who also found that there is a hypoplastic facial middle third with reduced nasal protrusion and a reduced mandibular region in Down syndrome individuals. ${ }^{10,12}$ From this study, the smaller mid-face measurements also indicates that the hypothesis in which that there is a decrease in the facial height especially the mid-face is proven and acceptable.

The reduction of the MFH and $\mathrm{LFH}$ is also consistent with the findings by Sforzaa $\mathrm{C}$ et al. as they found that DS individuals had a hypoplastic nose where the nose was significantly smaller (area) than in normal (reference) subjects, and that the nose it had a different shape (more flat angle of alar slope, more acute nasaltip angle). ${ }^{13}$ In addition, the vertical(nasal bridge length, nose height) as well as the different upper and lower lipswere reduced compare to the normal subjects.

In DS, their maxilla and mandible are generally less developed, thus resulting in a total reduced vertical facial height. This might possibly be due to abnormalities at the critical region of chromosome 21. Eventually, this leads to the disruption of the course of normal development, hence giving DS individuals the distinctive facial characteristic features as well as causing an increased risk in other medical problems associated with this genetic condition. 
In DS subjects, prior to any examination, a proper self-introduction and approach must be employed during the course of study. Failure to do so or to failure in making the child comfortable and at ease leads to difficulties in taking measurements or child's' total refusal in being measured.

From this study a few assumptions can be made, which is the type of DS the individuals has can be closely related to the child's attitude and IQ level. The more co-operative and intellectual the individual is, it can be assumed that the person has the Mosaicism or the Translocation type, which is as a whole is a less severe type of Down syndrome.

Another assumption is that, the facial features, although most DS individuals potrays same facial features, however, some may have a less severe facial dysmorphism, hence, it can be assumed that he or she has the Translocation or Mosaicism type. However, in order to prove the relevancy of this theory, karyo-typing must be done.

In addition, few improvements could be done to improve the study such as a longitudinal study in which a longer period of study time should be conducted, a larger number of samples should be examined to better validate the outcome, examiner should also learn more on the socialemotional functioning of the DS individuals as well as try spending more time with the children in order for the DS children to familiarise with outsiders.

\section{CONCLUSION}

There are significant differences with the MFH and LFH between DS and $\mathrm{R}$ children and UFH differences is non significant between these two populations.

\section{REFERENCES}

1. Lopes TS, Ferreira DM, Pereira RA, Veiga GV, Marins VMR. Assessment of anthropometric indexes of children and adolescents with Down syndrome. J Pediatria. 2008;84(4);350-6.

2. Khan R, Abdullah AA, Antony VV. Down Syndrome: A Case Report. Orthod J. 2008;1: 112-5.

3. Kolar JC, Salter EM. Craniofacial Anthropometry: Practical Measurement of the Head and Face for Clinical, Surgical, and Research Use. Charles C. Thomas 1997;81124;249-54.

4. Tortora GJ, Derrickson BH. Principles of Anatomy and Physiology. $11^{\text {th }}$ ed. Atlas and Registration Card. Wiley. 2006. p. 410-5.

5. National Down syndrome Society (NDSS). Down syndrome. Available from: http: / /www. ndss.org. [cited February 2011] 2011.

6. SAID. Down Syndrome: A review for Dental Professionals. Southern Association of Institutional Dentists (SAID). Module 2002. p. 3. 2-9.

7. Baral P, Lobo SW, Menezes RG, Kanchan T, Krishan K, Bhattacharya $S$ et al. An anthropometric study of facial height among four endogamous communities in the Sunsari district of Nepal. Singapore Med J. 2010;51(3):212-15.

8. Babbush CA, Fehrenbach MJ, Emmons $M$ and D.W. Nunez. Mosby's Dental Dictionary. $2^{\text {nd }} E d$. Mosby. Elsevier. St. Loius. 2008.

9. Jaswal S, Jaswal IJ. An Antrhopometric study of body size in Down syndrome. Indian J Pediatr. 1981 Jan-Feb;48(390):81-4.

10. Farkas LG. Anthropometry of the Head \& Face. $2^{\text {nd }}$ ed. Lippincott-Raven. 1994. p. 10-14.

11. Rakosi T, Jonas I, Graber TM. 1993. Color Atlas of Dental Medicine: Orthodontic-Diagnosis. AJO-DO. 1994;105(6):613.

12. Ferrario VF, Dellavia C, Zanotti G, Sforza C. Soft tissue facial anthropometry in Down syndrome subjects. J Craniofac Surg. 2004 May;15(3):528-32.

13. Ferrario VF, Dellavia C, Colombo A, Sforza C. Three-dimensional assessment of nose and lip morphology in subjects with down syndrome. Ann Plast Surg. 2004 Dec;53(6):577-83. 